\section{Leukaemia and wartime evacuation}

SIR - Evans notes in News and Views ${ }^{1}$ that Kinlen and colleagues ${ }^{2}$ have provided evidence consistent with the hypothesis that childhood leukaemia may be a rare response to an unidentified infective agent. Kinlen and colleagues find that leukaemia deaths in 'rural' new towns are greater than those in 'overspill' new towns. Most at risk from the putative leukaemia infection resulting from this population mixing are the $0-4$-year age group, which shows an observed/expected ratio for cases of 2.75 in the rural towns (compared with 0.95 for the overspill towns) in the early years following designation as new town. The authors suggest

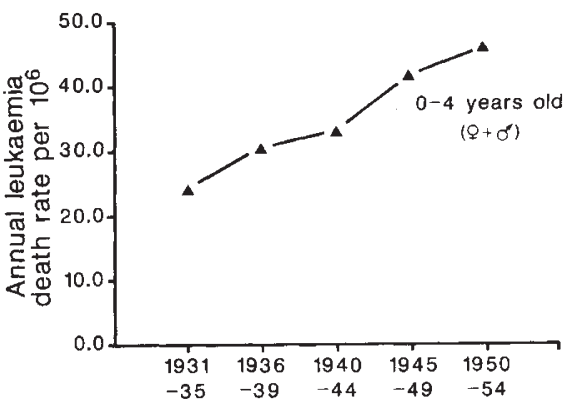

that a higher population density and the greater diversity of places of origin in the rural (compared with overspill) towns would cause more severe leukaemia epidemics since there would be greater opportunity for 'herd mixing' infection but less herd immunity.

If it is true that there is an infective basis for childhood leukaemia than an earlier and more extreme population mixing would have contributed markedly to the national childhood leukaemia statistics. As a result of evacuation in Britain during the Second World War, 827,000 unaccompanied children, 524,000 mothers with children under 5 years old as well as 13,000 pregnant women migrated from major conurbations into rural areas between 1 and 4 September 1939 (ref. 3). In those 5 days alone, almost half of the nation's schoolchildren moved from the cities. Further migration and re-migration occurred during the course of the war.

In contrast, average population influxes into the 14 new towns studied by Kinlen and colleagues were a mere 20,000 (rural) and 38,000 (overspill) from 1951 to 1966 . Yet the massive population mixing resulting from evacuation does not seem to have resulted in a surge of national childhood leukaemiat. The figure depicts data for leukaemia mortality of the relevant age group in England and Wales over the period 1931 to 1954. Against the unexplained steady rise in leukaemia mortality there is no evident sudden increase in the periods $1940-44$ nor $1945-49$.

Although extrapolation from global to local migration trends may be question- able, the data suggest that herd mixing may be an inadequate explanation for local increases in leukaemia incidence. In another critique of the herd-mixing hypothesis (based on lack of specificity of increased childhood cancer) it was suggested that "environmental aspects of increasing urbanisation" could contribute to the increased incidence of childhood leukaemia, and other childhood cancers, in new towns'. I have proposed that locally higher exposure to benzene as a result of greater car usage encouraged by higher salary/cost-of-living ratios in the new towns is one such environmental factor". The observation that residential traffic density in Denver correlates with child-

\section{Toroidal bubbles}

SIR - "Air-bubbles in water are usually rather deformed spheres. Daedalus reckons that toroidal bubbles should also be possible. He sees them as a form of two-phase vortex-ring - a toroidal airbubble stabilized by the centrifugal force of the toroidally spinning liquid around it." This extract' from Daedalus's article 'Bubbling down' shows that amusing and speculative ways of thinking can be important in science. Toroidal bubbles really exist, and were observed by me in 1982 during investigations into two-phase downflow of air and very viscous mineral oil in vertical tubes. They are manifestations of a new flow pattern, for which we have proposed ${ }^{2}$ the name 'stalactite flow'.

The photograph shows an example of toroidal bubbles inside a glass tube of internal diameter $25 \mathrm{~mm}$ for a liquid of viscosity $1.69 \mathrm{~Pa}$ s, surface tension 0.0363 $\mathrm{N} \mathrm{m}^{-1}$ and density $996 \mathrm{~kg} \mathrm{~m}^{-3}$. Toroidal bubbles have also been observed in a tube $15 \mathrm{~mm}$ in diameter. The flow pattern and the range over which it occurs are described in my thesis ${ }^{3}$ (which is in Polish); unfortunately, we have not been able to investigate this phenomenon in more detail because of the economic problems besetting science in Eastern Europe.

I also agree with Daedalus's opinion that his "interest is far from academic". The stalactite flow pattern could be applicable in multiphase flow reactors. Heat and mass transfer conditions should be favourable for toroidal bubbles, and may be better than in typical bubble column reactors. Stalactite flow could be especially useful for bioreactors which work with high viscosity liquids. In many biotechnology processes it is necessary to cultivate cells or bacteria in aerobic conditions with accurate control of

2. Troniewski, L. \& Spisak, W. Int. J. Multiphase Flow 13 257-260 (1987).

Spisak. W. thesis, Wroclaw Technical Univ. (1987)
1. Jones, D. Nature 343, 122 (1990) hood leukaemia (odds ratio $=4.7$ for $>10,000$ vehicles per day and 2.1 for $>500$ per day) ${ }^{7}$ is also consistent with the hypothesis that childhood cancers may be linked to carcinogens associated with the internal combustion engine.

SiMON P. WOLFF

Department of Clinical Pharmacology,

University College and Middlesex

School of Medicine,

University College London,

London WC1E 6JJ, UK

1. Evans, H.J. Nature 347, 712 (1990)

2. Kinien, L.J., Clarke, K. \& Hudson, C. Lancet 336, 577 (1990).

. Minns, R. The Domestic Front 1939-45 (Virago, London 1980)

Court Brown, W.M. \& Doll, R. Brit. Med. J. 1, 981 (1961)

. Muir, K.R., Graham, R., Parkes, S.E. \& Mann, J.R. Brit Med. J. 300, 676-677 (1990).

. Wolff, S.P. Nature 346. 517 (1990)

Savitz, D. \& Feingold, L. Scand. J. Work Envir. Hith 15 360-363 (1989)

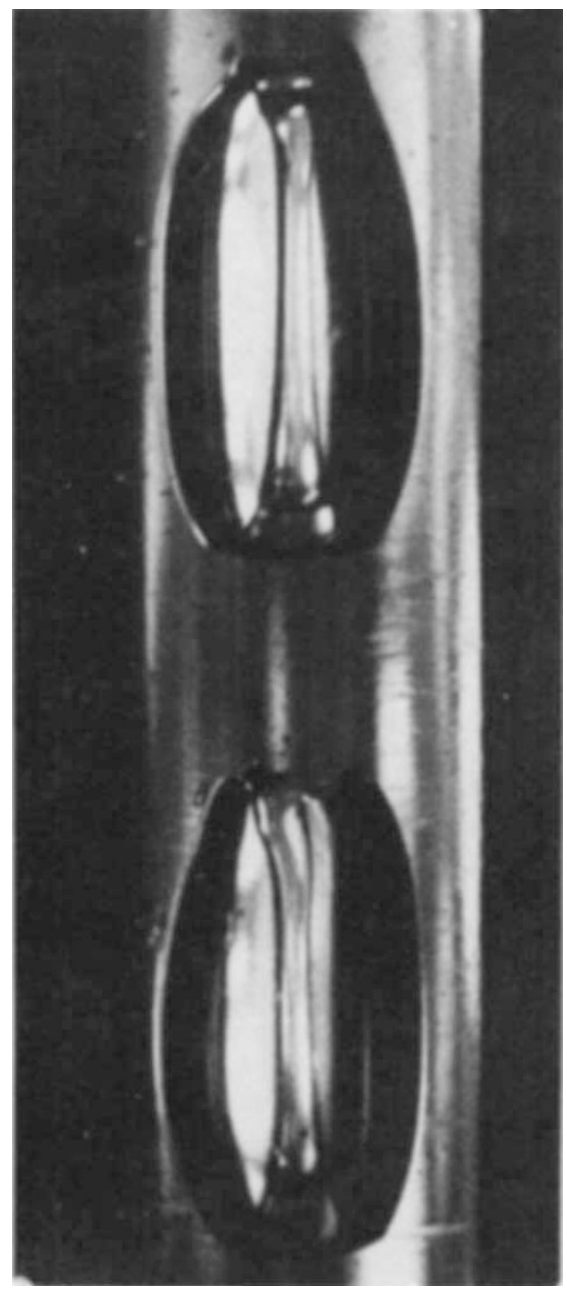

Toroidal bubbles in a tube of diameter $25 \mathrm{~mm}$. temperature, and the cells and bacteria have to be protected against mechanical damage as much as possible. Multitubular reactors working under the stalactite flow regime could be a new step in developing bioreactors.

Department of Heat Techniques and Chemical Engineering,

Opole Technical University,

ul. ZSP 5, 45-233 Opole, Poland 